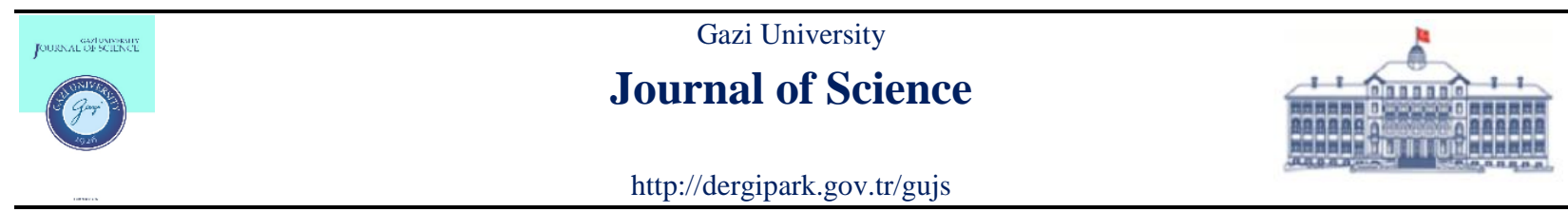

\title{
Electrical Performance Analysis of Thermoelectric Generating System with INC-MPPT Algorithm
}

\author{
Mohamed Elzalik ${ }^{1, *}$ (D) , Hegazy Rezk ${ }^{2,3}$ (D), Ramadan Mostafa ${ }^{1}$ (D), Jean Thomas ${ }^{4}$ (D) Emad Shehata $^{3}$ (D) \\ ${ }^{1}$ Process Control Technology Dept.,Faculty of Industrial Education, Beni-SuefUniversity, Beni Suef, Egypt \\ ${ }^{2}$ College of Engineering at WadiAddawaser, Prince Sattam Bin AbdulazizUniversity, Al-Kharj, KSA \\ ${ }^{3}$ Electrical Engineering Department,Faculty of Engineering, Minia University,Minya, Egypt \\ ${ }^{4}$ Electrical Engineering Department,Faculty of Engineering, Beni-SuefUniversity, Beni Suef, Egyp
}

\section{Highlights}

- The electrical performance of a TEG system has been analyzed with the INC-MPPT.

- DC-to-DC boost converter has been designed, simulated and implemented.

- Performance analysis of INC-MPPT control algorithms at different values of temperature difference.

- Modeled of Thermoelectric Generator system.

\section{Article Info \\ Received: $11 / 04 / 2019$ \\ Accepted: 20/09/2019 \\ Keywords \\ Thermoelectric Generators DC-DC boost converter waste heat recovery \\ Incremental Conductance; $M P P T$ \\ Energy Efficiency}

\begin{abstract}
Thermoelectric Generator (TEG) is a new trend in renewable energy issues that utilize heat energy to produce electricity from various waste energy sources. These sources are available from natural sources like geothermal and solar heat and recovering from many industrial processes. In this paper, the electrical performance of a TEG system has been analyzed when the Incremental Conductance - maximum power point tracker (INC-MPPT) control algorithm has been applied to maximize the energy conversion efficiency. The TEG system has been simulated, implemented and tested at different values of temperature difference. Simulation and experimental results show that, the proposed control algorithm can be operated at the maximum power point (MPP) of the TEG module at any operating condition with good accuracy and low fluctuation around this point. Also, the experimental results show that, the harvested power has been duplicated by more than six times by applying the INC-MPPT algorithm $(11.9 \mathrm{~W})$ in comparing with connection without MPPT $(1.9 \mathrm{~W})$ at the same resistive load $(16 \Omega)$, the same applied temperature and the same operating conditions.
\end{abstract}

\section{INTRODUCTION}

Thermoelectric Generator is a renewable energy source which can minimize the release of $\mathrm{CO}_{2}$ and other harmful gases produced from burning fossil fuel. Heat energy from different renewable energy sources such as geothermal, solar [1,2], or waste heat from any operating process such as power plants can be converted into DC power by applying thermoelectric generating technology depending on the Seebeck effect.

Nowadays, Thermoelectric generators are widely expanded commercially. They have been inserted in different applications including small scale which produce only microwatts and large scale which produce kilowatts $[3,4]$. Space and military suppling equipment were the most to used TEG in isolated, hostile fields as these generators have light weight and can operate in harsh environments without maintenance. It can be incorporated in many systems that liberate heat during their operation like stoves and automobiles, where they not only produce electricity but also increase the efficiency of the system. Many sensors that are based in their work on detecting heat changing in a system also are developed using TEG to translate these changes as electrical output voltage. TEG also has been used as a power source in medical equipment and human luxuries like watches using human body heat [5]. 
Up to date, many trails have been reported to improve the efficiency of the TEG modules by improving the semiconductor materials [6, 7], the heat exchangers that provide different heat energy on the TEG sides to decrease the thermal resistance[8], and improving the electronic interface circuit with the external load to obtain the output power $[9,10]$.

The main challenge facing the output power of the thermoelectric generator is the instability which is affected directly by the temperature applied. Such as most renewable energy sources like photovoltaic cells and wind turbine, TEG depends on the operating conditions[11]. Therefore, a TEG system needs a control algorithm to transfer the maximum generated power continuously to the load at any operating condition[12]. This occurs when the external load equals the module internal resistance [13].

In most practical applications, the different temperature applied on the TEG module sides is not constant, as a consequence, the electrical output voltage of the module is affected directly by these changes and doesn't work or extract the maximum power. To overcome this problem, the external load must be connected with the TEG module via a DC-DC boost converter integrated with a MPPT control algorithm to adjust the load resistance with the internal resistance and maximize the harvested output power at any variation in temperature at different operating conditions.

There are several algorithms that were reported for MPPT in photovoltaic (PV)systems[14, 15], and most of these techniques can be used in TEG systems. Incremental Conductance (INC) is one of the most popular algorithms applied in the PV systems, because this method provides advantages over other techniques including speed, accuracy and less fluctuation around the maximum power point $[14,16]$.

In this paper, TEG test bench including the design of the heat exchangers is proposed to simulate different operating conditions of waste heat energy sources. A design of a TEG system with a DC- to DC boost converter integrated with incremental conductance (INC-MPPT) is analyzed and simulated using MATLAB-Simulink and implemented with an Arduino microcontroller. The Arduino controls the duty cycle of the DC-DC boost converter to maximize the harvested output power from the TEG. Also, it is used as a data acquisition system to measure the electrical current, voltage and temperature of the TEG module's cold and hot sides and send it to the personal computer. Finally, the electrical performance of the TEG system is analyzed and compared with and without applying INC-MPPT algorithm.

\section{MODELING OF THE THERMOELECTRIC GENERATOR}

Up to date, semiconductor pellets are the basic units used to fabricate the thermoelectric generator module. $\mathrm{p}$ and n-type semiconductors pellets are arranged alternatively forming thermocouples connected in series to increase the output voltage of the TEG module. They are stacked between two ceramic wafers forming a sandwich-like TEG module as illustrated in Figure 1.

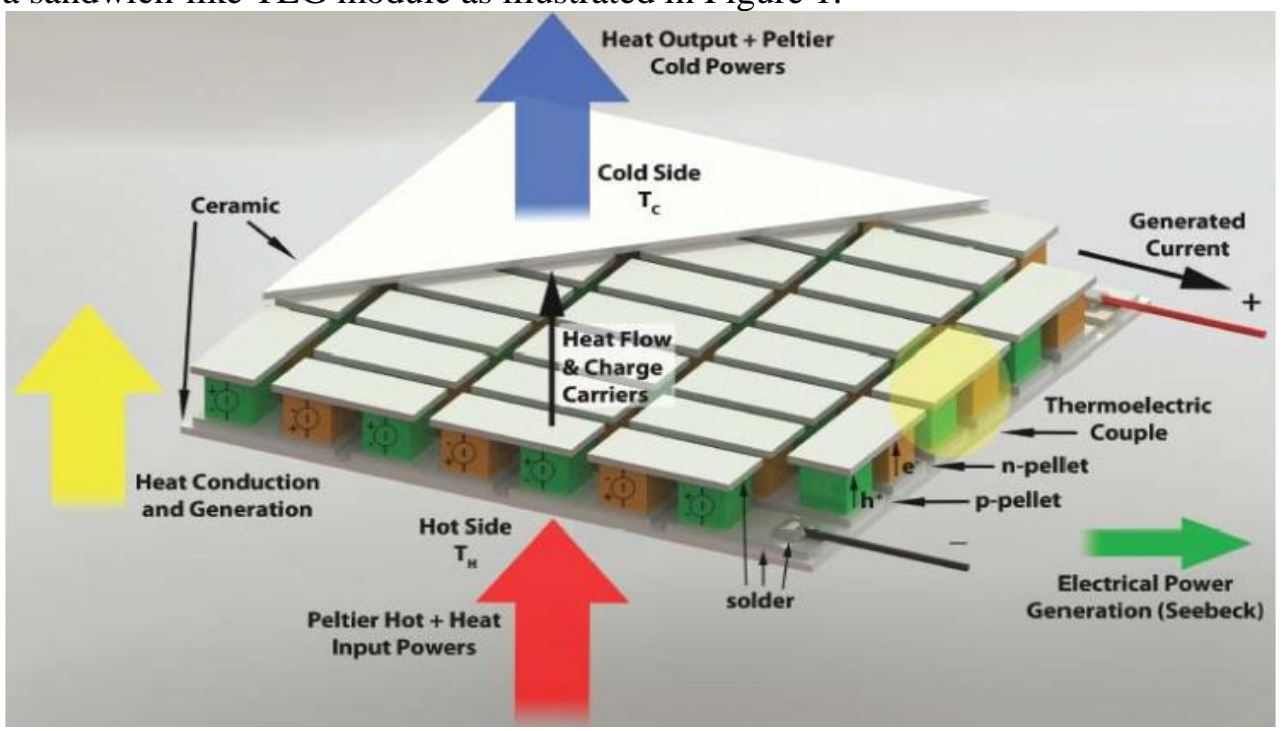

Figure 1. Thermoelectric generator constructions [15] 
Thermoelectric generation technology is based on Seebeck Effect to convert the heat energy to electrical power. When a temperature difference is applied on the TEG module's sides, open circuit voltage $\left(V_{o c}\right)$ will be generated on its terminals. This voltage mainly relies on the Seebeck coefficient $(\alpha)$ and the value of the temperature difference $(\Delta T)$. Open circuit voltage can be calculated by the following relation[10, 17]:

$V_{o c}=\alpha \times \Delta T$.

The first law of thermodynamics state that the heat energy runs from the high value temperature to the low value temperature $\left(Q_{h} \rightarrow Q_{c}\right)$ at heat energy equilibrium as shown by the followings[10, 18]:

$$
\begin{aligned}
& Q_{h}=\alpha I_{\text {teg }} T_{h}+K \Delta T-\frac{1}{2} I_{\text {teg }}{ }^{2} R_{\text {int }} \\
& Q_{c}=\alpha I_{\text {teg }} T_{c}+K \Delta T+\frac{1}{2} I_{\text {teg }}{ }^{2} R_{\text {int }},
\end{aligned}
$$

where $Q_{h}$ denotes the heat current at the hot side, $Q_{c}$ is the heat current at the cold side, $R_{\text {int }}$ is the total pellets internal resistance, $K$ is the thermal conductance, $\Delta T$ is the difference between the TEG sides temperature $\left(\Delta T=T_{h}-T_{c}\right)$ and $\alpha$ is the Seebeck coefficient.

The TEG module output power can be evaluated as the difference in the heat energy applied $\left(Q_{h}-Q_{c}\right)$ and estimated by the following relation

$$
P_{\text {teg }}=Q_{h}-Q_{c}=\alpha \Delta T I_{\text {teg }}-I_{\text {teg }}^{2} R_{\text {int }}=\left(\alpha \Delta T-I_{\text {teg }} R_{\text {int }}\right) I_{\text {teg }}=V_{\text {teg }} I_{\text {teg }}
$$

where $V_{\text {teg }}$ is the TEG output voltage applied on a load resistance $R_{L}$.

TEG module can be represented by the electrical equivalent circuit that consists of a voltage source $\left(V_{o c}\right)$ which is connected to an electrical resistance in series $\left(R_{\text {int }}\right)$ and both are connected with an electrical load $\left(R_{L}\right)$ as presented in Figure 2.

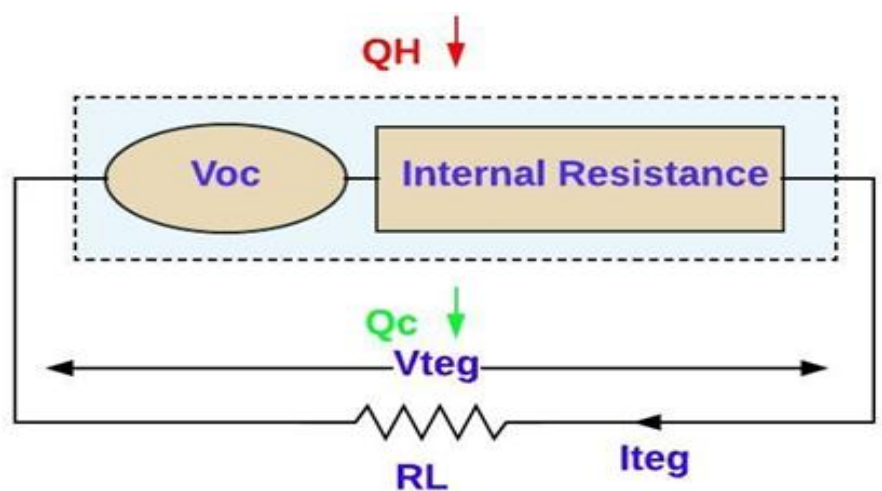

Figure 2. Equivalent circuit of the TEG module

By applying the Ohm's Law to the TEG module equivalent circuit, the TEG output voltage $\left(V_{\text {teg }}\right)$ applied on the load resistance $R_{L}$ can be determined by the following relation

$$
V_{\text {teg }}=\alpha \Delta T-I_{\text {teg }} R_{\text {int }}=V_{\text {oc }}-I_{\text {teg }} R_{\text {int }}=I_{\text {teg }} R_{L} \text {. }
$$

Voltage $\left(V_{m p p}\right)$, current $\left(I_{m p p}\right)$ and power $\left(P_{m p p}\right)$ at the maximum power point (MPP) can be given by the following equations

$$
\begin{aligned}
& V_{m p p}=\frac{\alpha \Delta T}{2}=\frac{1}{2} V_{o c} \\
& I_{m p p}=\frac{\alpha \Delta T}{2 R_{\text {int }}}=\frac{V_{o c}}{2 R_{\text {int }}}
\end{aligned}
$$




$$
P_{m p p}=V_{m p p} I_{m p p}=\frac{\alpha^{2} \Delta T^{2}}{4 R_{\text {int }}}=\frac{V_{o c}^{2}}{4 R_{\text {int }}} .
$$

The electrical characteristics specifications of the commercial TEG modules HZ-14HV shown in Table 1. [19], have been used for the simulation model using MATLAB-Simulink. The same TEG module (HZ14HV) has been used in the experimental test for this study.

Table 1. TEG HZ-14HV module characteristics

\begin{tabular}{|l|l|}
\hline Parameters & Values \\
\hline $\mathrm{T}_{h}$ & $250{ }^{\circ} \mathrm{C}$ \\
\hline $\mathrm{T}_{c}$ & $50{ }^{\circ} \mathrm{C}$ \\
\hline$V_{O C}$ & $7.91 \mathrm{~V}$ \\
\hline$I_{S C}$ & $7.979 \mathrm{~A}$ \\
\hline$R_{-} a t \_m p p$ & $0.991 \Omega$ \\
\hline$V_{\_} a t \_m p p$ & $3.95 \mathrm{~V}$ \\
\hline$I \_a t \_m p p$ & $3.9895 \mathrm{~A}$ \\
\hline$P \_a t \_m p p$ & $15.7747 \mathrm{~W}$ \\
\hline
\end{tabular}

\section{DC-DC CONVERTER AND INC-MPPT CONTROL ALGORITHM}

The circuit of the TEG system to harvest the maximum power involving a DC-DC converter integrated with INC-MPPT algorithm is displayed in Figure 3. The main function of the INC-MPPT algorithm is to move the electrical operating point of a load by receiving the measured values of the TEG output voltage and/or current and changing the pulse width modulation (PWM) on the DC-DC boost converter according to the characteristics of the external load, therefore a TEG module operates at the estimated voltage, current and resistance so that, the maximum generating power will be transferred to the load.

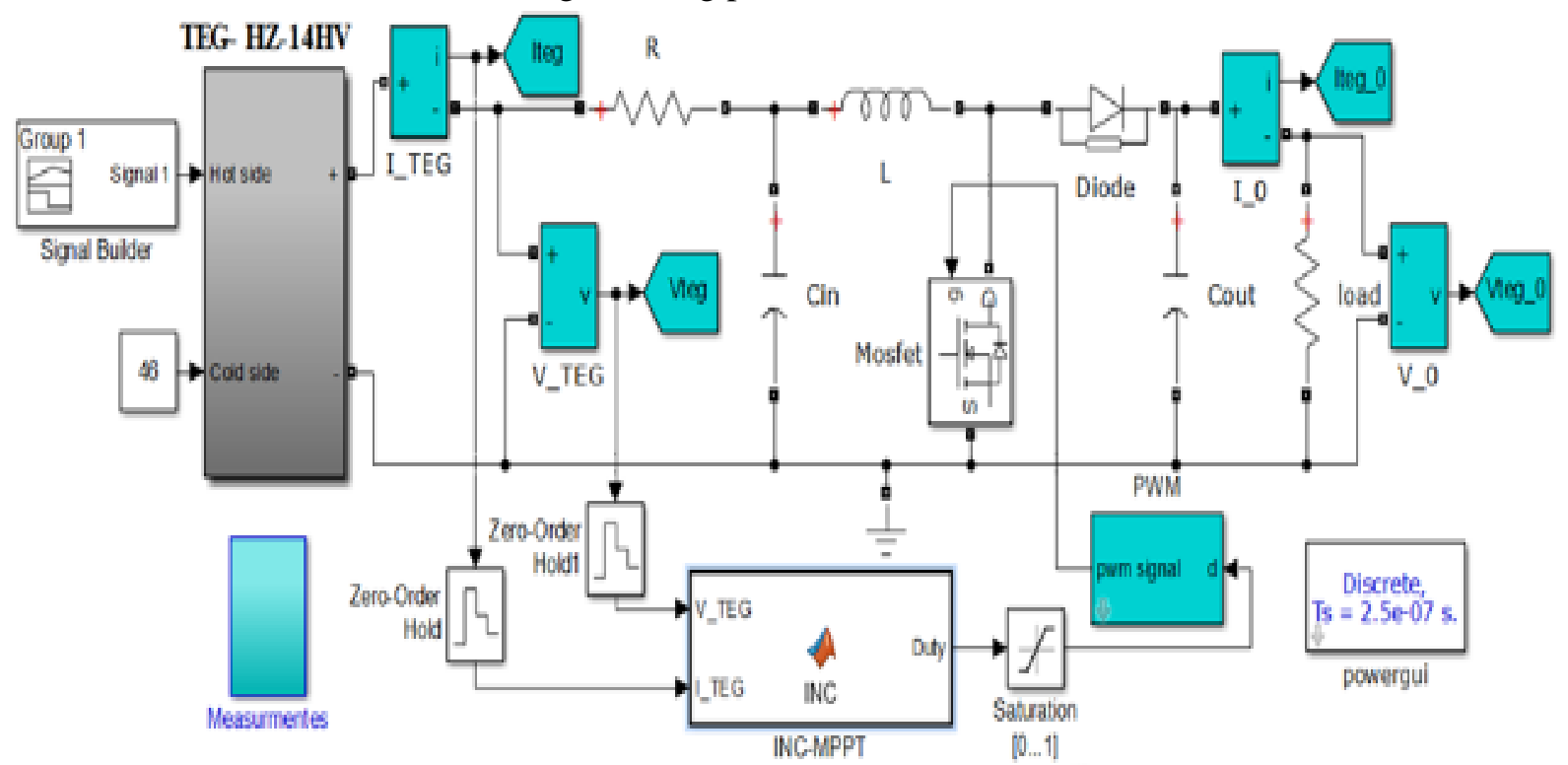

Figure 3. MATLAB/Simulink models of INC-MPPT and HZ-14HV TEG module

The DC-DC boost converter is designed by applying the following equations to select the optimal values of the inductor and capacitors to operate in the continues mode [20]. The converter duty cycle is the most important key for selecting DC-DC boost converter components and controlling the DC-DC converter to maximize the output power from the TEG system and it can be given from the following relation:

$D=1-\frac{V_{\text {in (min })} \times \eta_{\text {conv }}}{V_{\text {out }}}$ and $0 \leq D \leq 1$, 
where $V_{i n(\min )}$ is the minimum value of the input voltage that can be supplied to the converter, $\eta_{\text {conv }}$ is the efficiency of the converter and $V_{\text {out }}$ is the required output voltage given by:

$$
V_{\text {out }}=\frac{1}{1-D} \times V_{\text {in }} \text {. }
$$

The inductor value must be greater than the minimum inductor $\left(L_{\min }\right)$ as given by:

$$
L_{\text {min }} \geq \frac{V_{\text {in }} \times\left(V_{\text {out }}-V_{\text {in }}\right)}{\Delta I_{L} \times F_{S W} \times V_{\text {out }}},
$$

where $F_{S W}$ is the switching frequency applied on the MOSFET and $\Delta I_{L}$ is the ripple current for the inductor. It can be estimated from $20 \%$ to $40 \%$ from the maximum output current $I_{\text {out (max) }}$ given by.

$$
\begin{aligned}
\Delta I_{L} & =0 \cdot 2 \times I_{\text {out }(\max )} \times \frac{V_{\text {in }}}{V_{\text {out }}} \\
\Delta I_{L} & =\frac{V_{\text {in }(\min )} \times D}{F_{S W} \times L} .
\end{aligned}
$$$$
\text { or }
$$

Maximum output current of the power electronic switches (MOSFET $I_{S W(\max )}$ and Diode $I_{D(\max )}$ ) can be estimated from the following equations respectively:

$$
\begin{aligned}
& I_{S W(\max )}=\left[\frac{\Delta I_{L}}{2}+\frac{I_{\text {out }(\max )}}{(1-D)}\right] \\
& I_{D(\max )}=I_{\text {out }(\max )} .
\end{aligned}
$$

The minimum value of the input capacitor can be selected depending on the stability requirement of the input voltage for the peak current of a DC-DC boost converter. Also, the output capacitor value must be greater than the minimum value $C_{\text {out }(\min )}$ to decrease the ripple of the output voltage as given by:

$$
C_{\text {out }(\min )} \geq \frac{I_{\text {out }(\max )} \times D}{\Delta V_{\text {out }} \times F_{S W}} \text {. }
$$

DC-DC boost converter was simulated and implemented with 80NF70 power MOSFET, TLP250 MOSFET Driver, STPS2045 diode, $0.5 \mathrm{mH}$ inductor, $20 \mathrm{KHz}$ switching frequency, $16 \Omega$ load resistance, $1000 \mu F$, $1800 \mu F$ input and output capacitors.

INC-MPPT control algorithm depends on the power derivative with respect to that voltage is zero at the maximum power point as written in Equation (17) and the basic rules of INC-MPPT have been presented in Equation (18)

$$
\begin{aligned}
& \frac{\mathrm{d} P_{T E G}}{\mathrm{~d} V_{T E G}}=0 \Rightarrow \frac{\mathrm{d}\left(V_{T E G} I_{T E G}\right)}{\mathrm{d} V_{T E G}}=I_{T E G}+V_{T E G} \frac{d I_{T E G}}{d V_{T E G}}=0 \\
& \left\{\begin{array}{cc}
\frac{\Delta I_{T E G}}{\Delta V_{T E G}}=-\frac{I_{T E G}}{V_{T E G}} & \text { at } M P P ; \\
\frac{\Delta I_{T E G}}{\Delta V_{T E G}}>-\frac{I_{T E G}}{V_{T E G}} & \text { at left of } M P P ; \\
\frac{\Delta I_{T E G}}{\Delta V_{T E G}}<-\frac{I_{T E G}}{V_{T E G}} & \text { at Right of } M P P ;
\end{array}\right.
\end{aligned}
$$




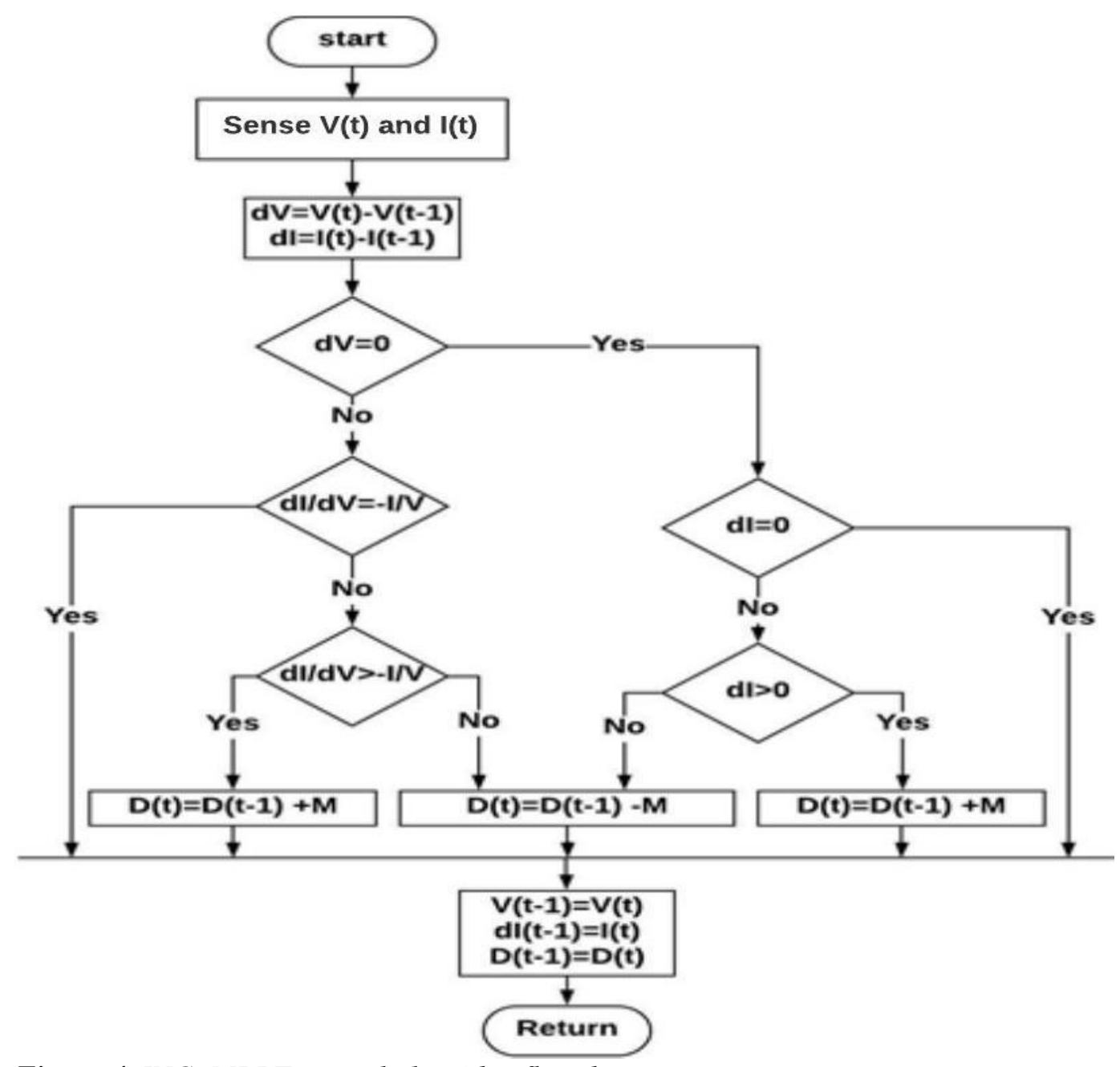

Figure 4. INC-MPPT control algorithm flowchart

The INC-MPPT control algorithm flowchart which has been used in the simulation model and implemented on the Arduino microcontroller is shown in Figure 4. The control algorithm is started by measuring the output current and voltage of TEG module and according to the rules (in Equation (18) and in Figure 4), the duty cycle $(D)$ has been increased or decreased by step value $(M)$ to estimate directly the optimal value of $(D)$ which transfers the maximum power to the load.

\section{EXPERIMENTAL SETUP}

The proposed thermoelectric generator test bench has been designed to test the thermoelectric generator module at different operating conditions as shown in Figure 6. Several components are involved in this system:

- A heat exchanger copper block with dimensions $200 * 120 * 10 \mathrm{~mm}$ has been used to provide the heat transferring from the heat energy supplier to the hot side of the TEG module, and another heat exchanger made of a copper block with dimensions $200 * 120 * 20 \mathrm{~mm}$ has been used on the cold side to absorb the heat from the cold side of the TEG module and increase the different in temperature between the both sides of the TEG .

- Mechanical frame to integrate and hold the TEG module in between the heat exchangers.

- mechanical springs have been used to distribute the mechanical pressure regularly on the TEG module surface. 
- Chiller and AC water pump; chiller is applied to cool the water and water pump is proposed to cycle this cold water through the cold side exchanger.

- Electrical heater (1500 watt) with TCNL4S temperature controller to adjust the hot side temperature

- DC-to-DC boost converter connected in series between the TEG module and a resistive load.

- Current, voltage and temperature sensors and Arduino Mega-2560 microcontroller to control and monitor the TEG voltage, current, power and values of temperature on the TEG sides.

The block diagram of the TEG testing system with the INC-MPPT is presented in Figure 5 and the empirical setup is presented in Figure 6. The TEG module has been placed between the hot and cold side heat exchangers. A mechanical pressure $(180(p s i))$ has been applied regularly on the TEG module surface. The TEG module is connected to $16 \Omega-60 \mathrm{~W}$ resistive load through the DC-DC boost converter. The Arduino controls the Pulse width modulation (PWM) of a DC-DC boost converter to maximize the harvested output power according to the INC-MPPT control algorithm. Also, it is used as a data acquisition system to measure the electrical current, voltage and temperature of the TEG module's cold and hot sides and send them to the personal computer. Finally, all measurements are recorded on computer, the electrical performance of the TEG system is analyzed when the INC-MPPT algorithm is applied at different operating conditions.

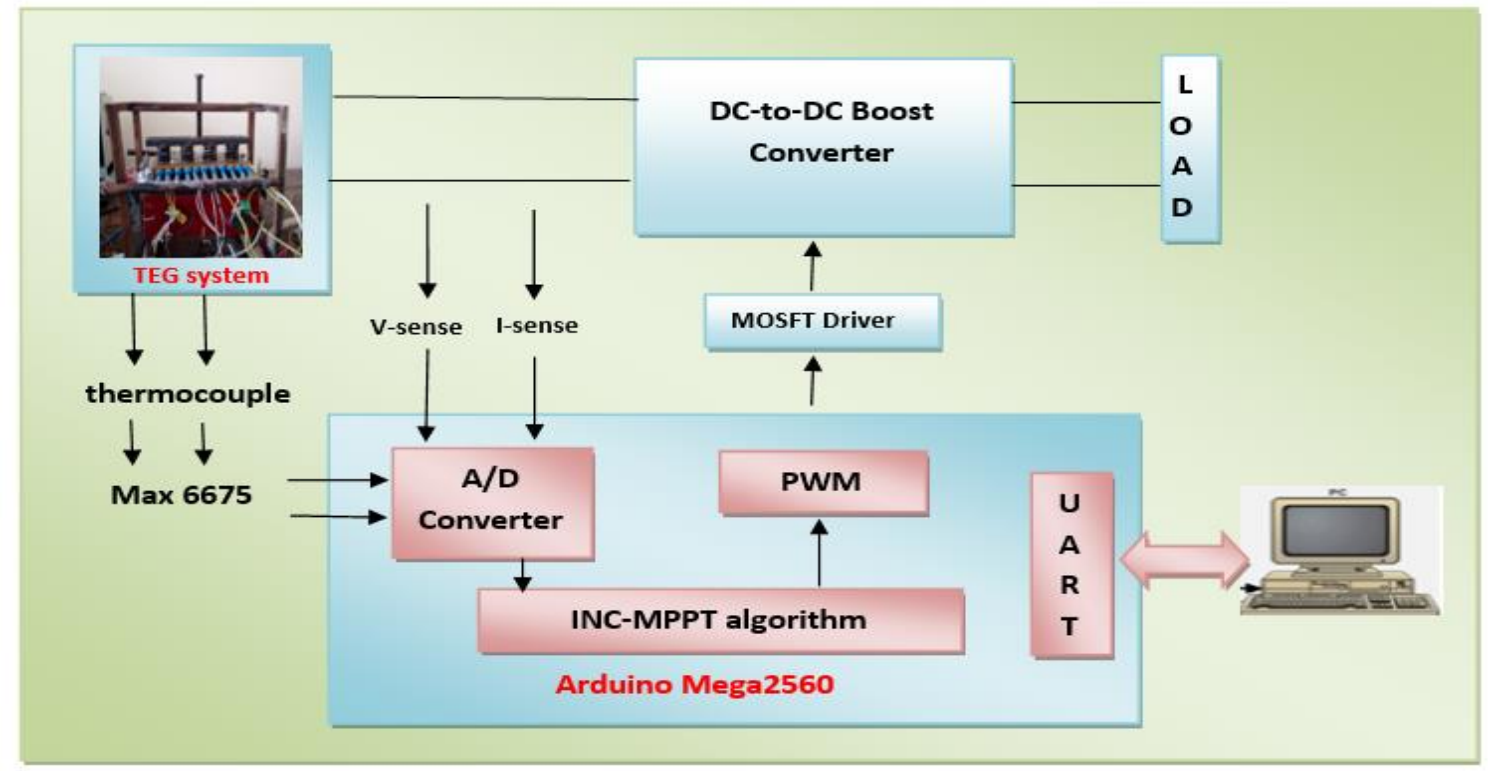

Figure 5. The block diagram of the proposed INC-MPPT system 


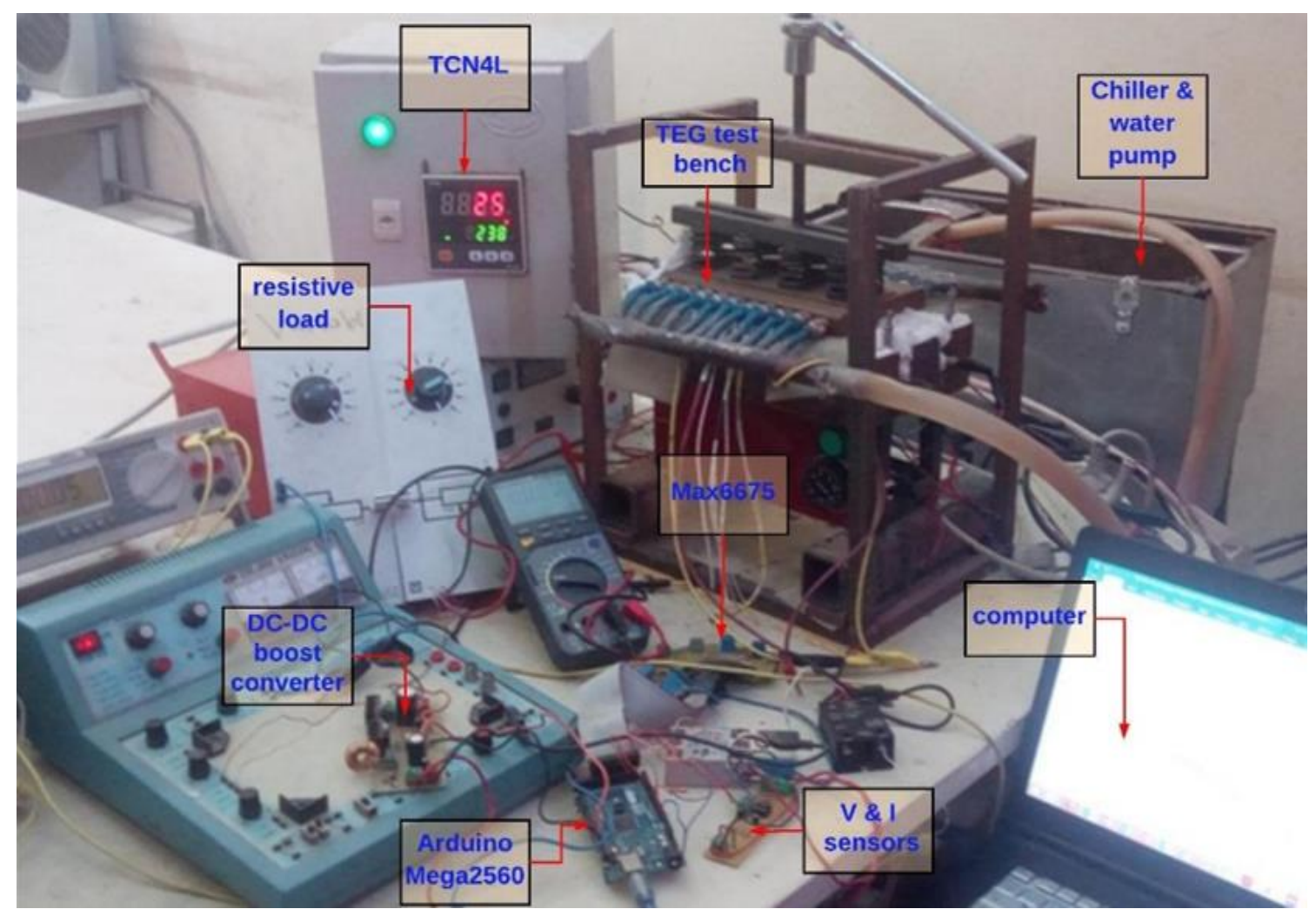

Figure 6. Hardware setup of the TEG testing system with the INC-MPPT

TEG module has been placed between the two heat exchangers with the applied mechanical pressure and tested at different operating conditions. Also, it has been connected to the DC-DC converter integrated with the INC-MPPT control algorithm. TEG system was tested at fixed value of temperature of the cold side and various values of the hot side temperature, also tested when the both sides temperature are increased together and tested at rapid change in the hot and cold side temperature of the TEG module to analyze and examine the electrical performance of the proposed TEG system with INC-MPPT at different operating conditions. At all test cases, the current, voltage and temperature on the hot and cold side have been measured every $500 \mathrm{~ms}$ and stored on computer using Arduino microcontroller. The experimental results of the different tests will be discussed in the following section.

\section{RESULTS AND DISCUSSION}

The proposed TEG system has been simulated using MATLAB-Simulink as shown in Figure 3 and it has been tested at $46^{\circ} \mathrm{C}$ cold side temperature and different values of hot side temperature to examine the electrical performance of the INC-MPPT control algorithm at rapid changes in temperature difference on the TEG module which were being changed every $0.1 \mathrm{~ms}$ from $125^{\circ} \mathrm{C}$ to $221^{\circ} \mathrm{C}$ at the final simulation time $(0.5 \mathrm{~ms})$ as shown in Figure 7 . 


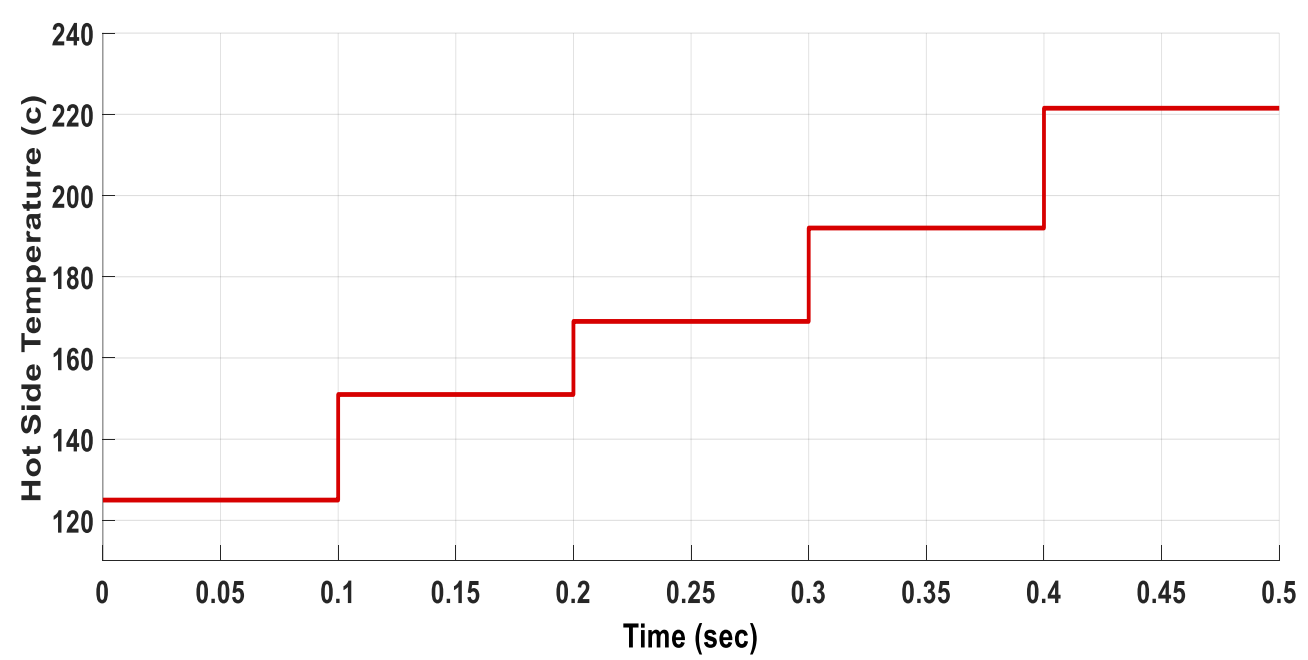

Figure 7. Different values of the hot temperature $\left(125 ; 151 ; 169 ; 192 ; 221^{\circ} \mathrm{C}\right)$ applied on the simulation test

DC-DC boost converter has been simulated including the real parameters of the power electronic switches (MOSFT and diode), inductor and capacitors. Simulation results of the input and output power, voltage and current of the DC-DC boost converter with INC-MPPT at different values of the hot side temperature are shown in Figure 8. Changing in the converter duty cycle to track the maximum output power during varying the applied temperature on the hot side is shown in Figure 9. The heat energy of the hot side $Q_{h}$ and cold side $Q_{c}$ (from Equation (2) and Equation (3) respectively), the efficiency of the TEG module and the efficiency of the DC-DC boost converter have been estimated and shown in Figure 10.
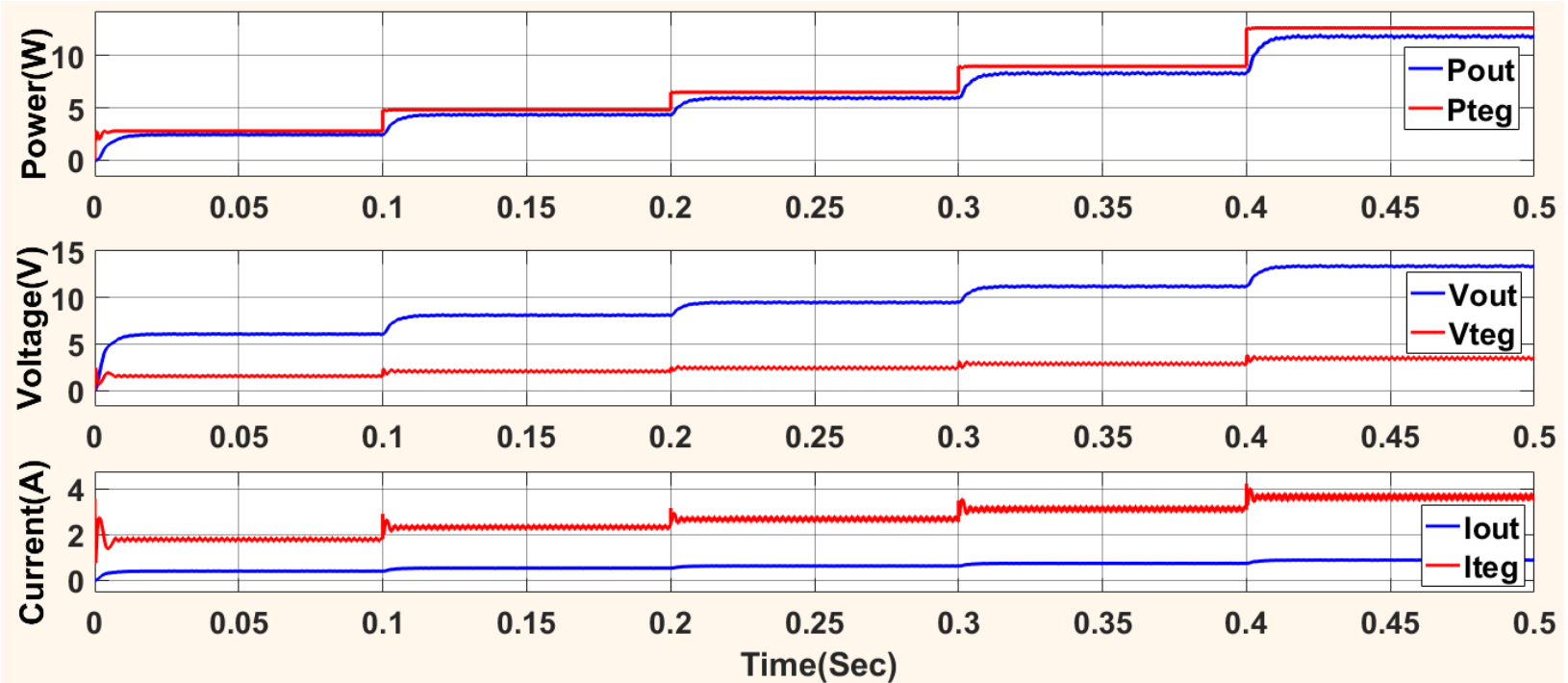

Figure 8. Input and output power, voltage and current of the DC-DC boost converter with INC-MPPT at the different values of the applied temperature 


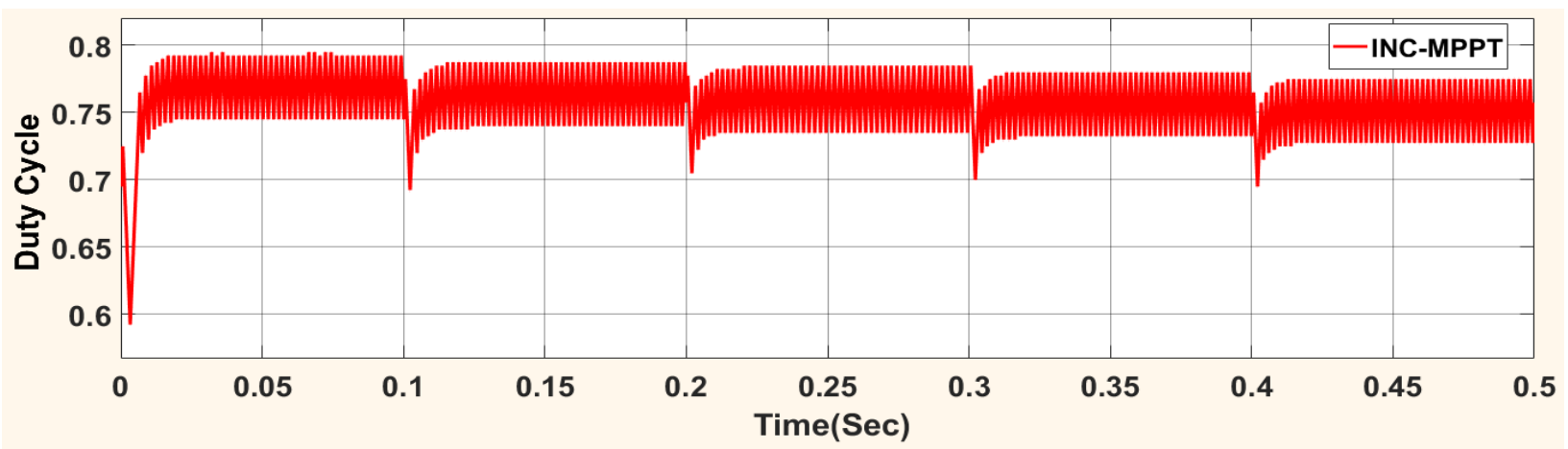

Figure 9. Duty cycle at the different values of the hot side temperature.

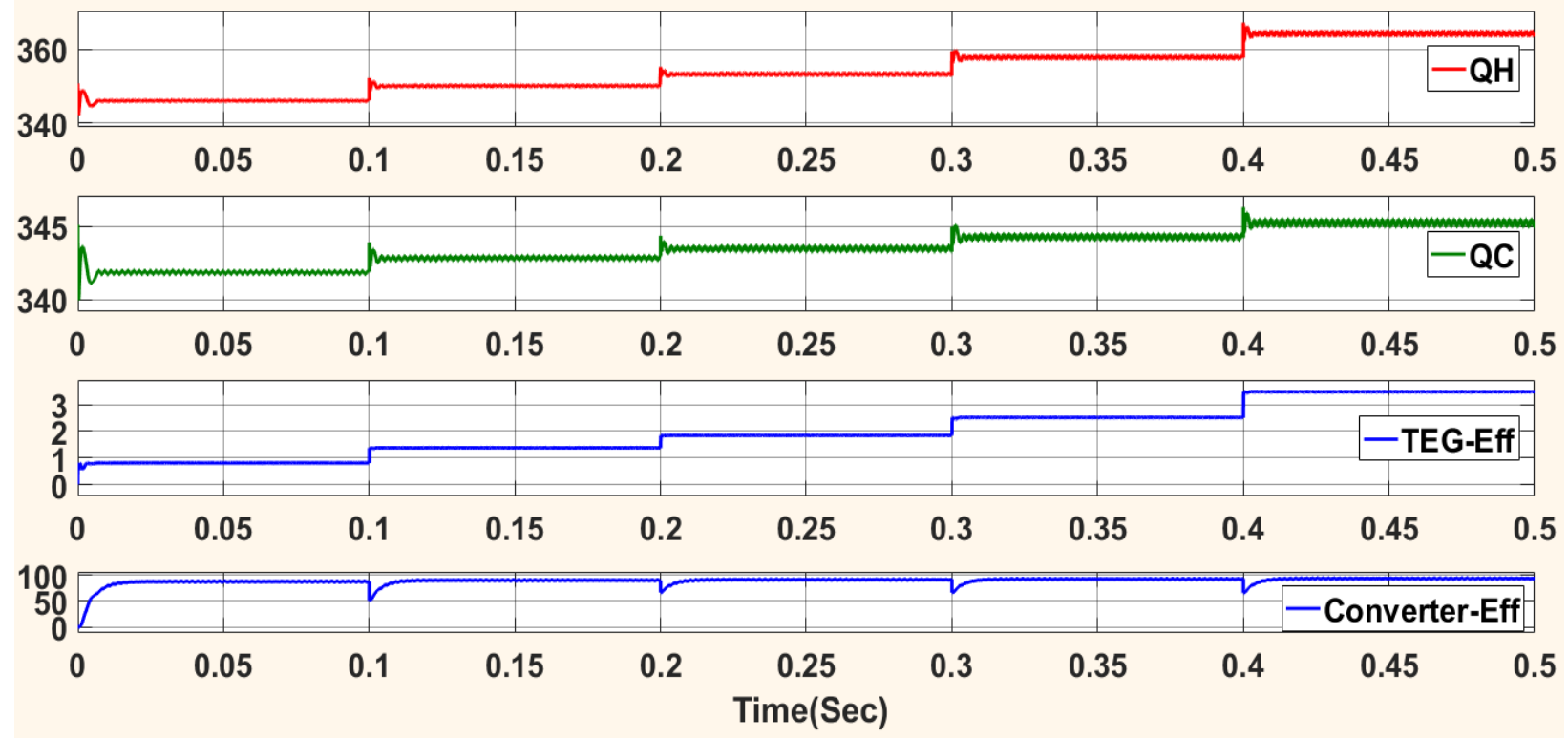

Figure 10. Simulation results of the heat energy, TEG module and converter efficiency at INC-MPPT at various values of the hot side temperature

The experimental tests have been started by adjusting the both sides temperature of the TEG module, as the Arduino microcontroller was measuring the current, voltage and hot and cold side temperature every $500 \mathrm{~ms}$ and saving them on computer. TEG module has been tested at different operating conditions.

Generally, four experimental tests have been manifested and analyzed. In the first test, the implemented test has been adjusted at the same conditions inserted in the simulation model. The cold side temperature was set at $46^{\circ} \mathrm{C}$ and the hot side temperature was set at $125 ; 151 ; 169 ; 192 ; 200 ; 221^{\circ} \mathrm{C}$. TEG module has been tested at each temperature difference to investigate the INC-MPPT control algorithm when it is applied to recover the low waste heat energy in the range between 120 to $220^{\circ} \mathrm{C}$. Temperature differences between the both sides were obviously constant during the six applied temperature as shown in Figure 11(a). The output current, voltage and power of the TEG module when the INC-MPPT algorithm is applied to maximize the output power are shown in Figure 11(b, c \& d) through $17 \mathrm{sec}$ timing test. The experimental results show that, the proposed TEG system including the INC-MPPT control algorithm can achieve the maximum output power through $1.5 \mathrm{sec}$ with less fluctuation around the MPP as shown in Figure 11(d). 


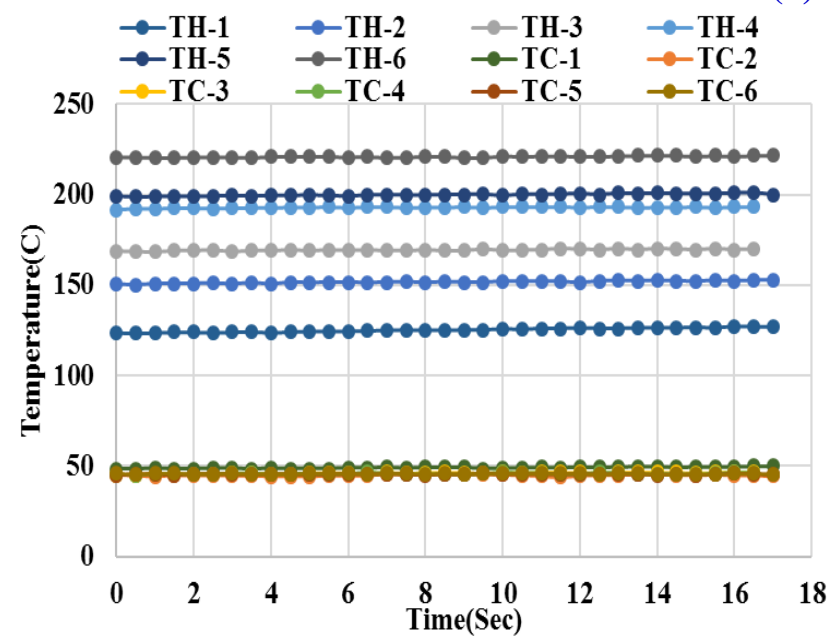

(c)

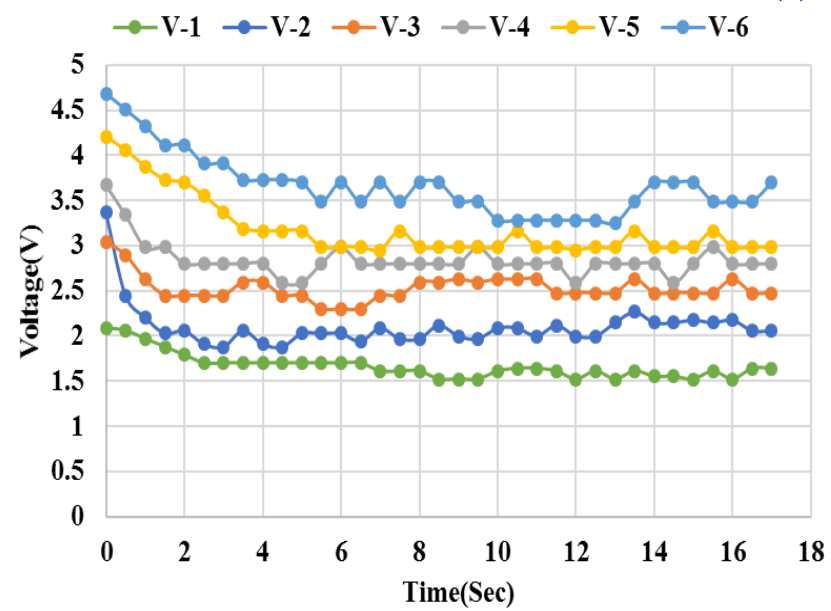

(a)

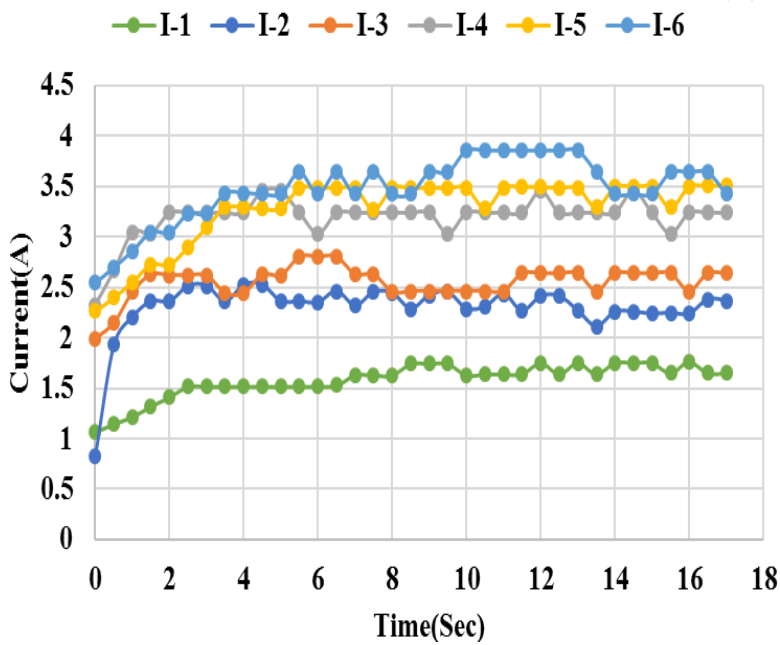

(b)

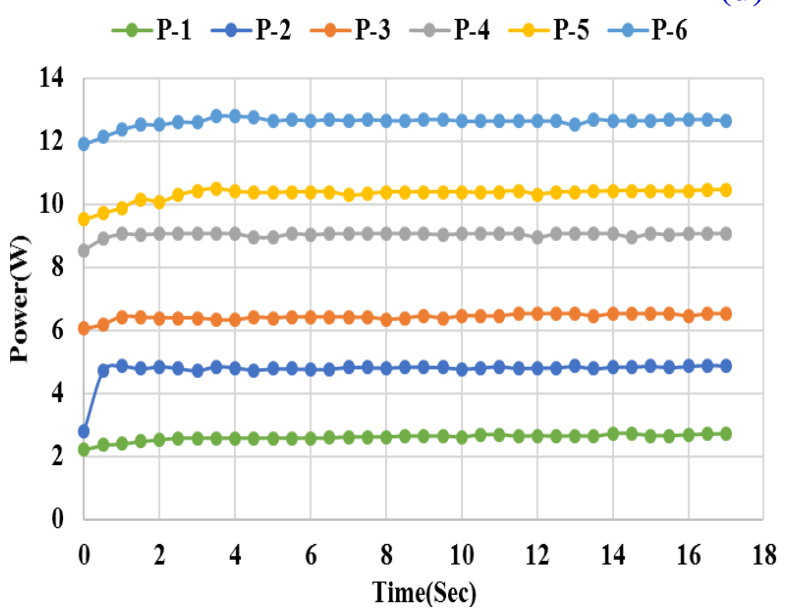

Figure 11. Experimental measurements of INC-MPPT at constant temperature and different values of temperature applied on the hot side, (a) hot and cold sides temperature, $(b)$ current, $(c)$ voltage and (d) power of the INC-MPPT

In the second test, TEG system with the INC-MPPT has been tested when the hot side temperature was being increased from $160.25^{\circ} \mathrm{C}$ to $187.7^{\circ} \mathrm{C}$ through a full-time test $(192 \mathrm{sec})$, and the cold side temperature is been increased from $47.5^{\circ} \mathrm{C}$ to $55^{\circ} \mathrm{C}$ though the first part of the test (through the time from 0 to $62.2 \mathrm{sec}$ ). This keep the temperature difference between the both sides around $120^{\circ} \mathrm{C}$ at this time as shown in Figure 12(a). While through the second part of the test (through the time from63 to $192 \mathrm{sec}$ ) the cold side temperature values is being decreased from $54.75^{\circ} \mathrm{C}$ to $32.75^{\circ} \mathrm{C}$. The temperature difference, therefor, is being increased in this time as shown in Figure 12(a). From Figure 12(b)

The results of this test show that, the output power, voltage and current are extremely constant through the first part of the test (till 62.2sec) as the temperature are constant between the both sides and by increasing the temperature difference regularly through the second part of the test (through the time from $63 \mathrm{sec}$ to the end of the test), the output power, voltage and current increase as shown in Figure 12(b). From this test, the changes in the temperature difference directly affect the output power, voltage and current. 
(a)
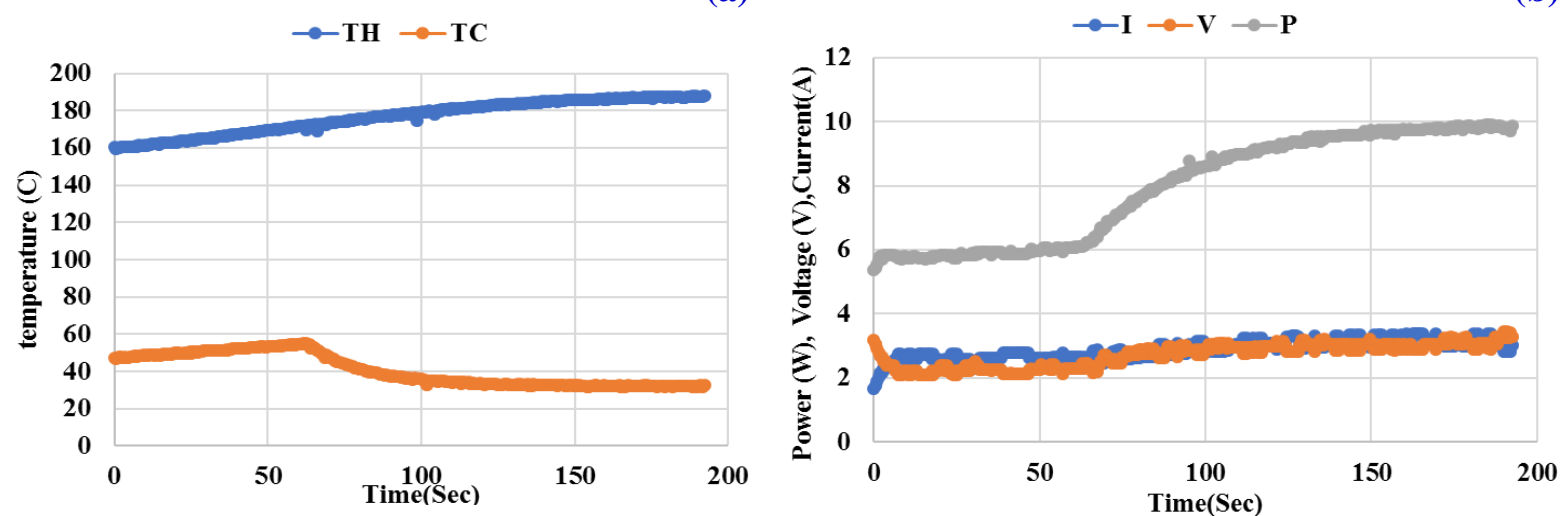

(b)

Figure 12. Experimental measurements of INC-MPPT when the hot side is increased, and the cold side is decreased, (a)hot and cold sides temperature, (b) current, voltage and power at this temperature

In the third test, the electrical performance of the INC-MPPT has been tested when the both side's temperature of the TEG module are changed randomly. As shown in Figure 13(a), temperature of the hot side is increased regularly while the cold side temperature increases and then drops (around the time $270 \mathrm{Sec}$ ) which increases the net temperature difference between the both sides and increases again till the end of the test. The output power, voltage and current change according to the temperature difference applied and very fast response of the output power can be observed during the sharp increase in the temperature difference as shown in Figure 13(b). Experimental results in Figure 12(b) and Figure 13(b) show that, the output power directly depends on the value of the temperature difference between the both sides of the TEG module.

(a)

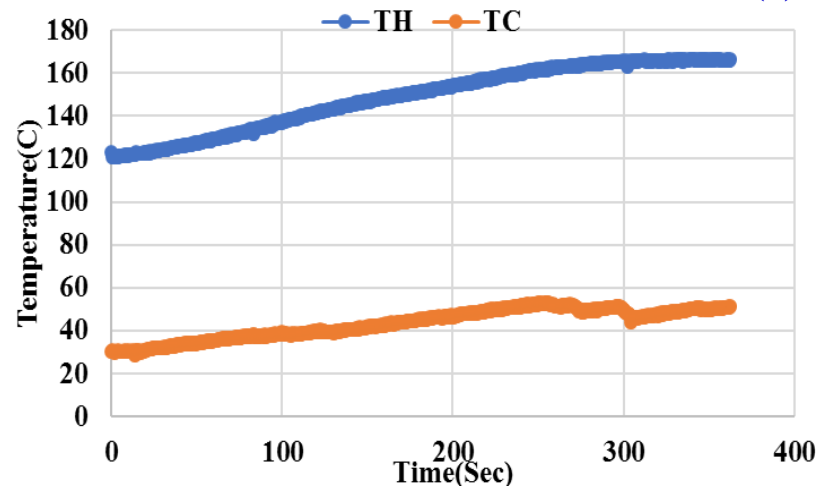

(b)

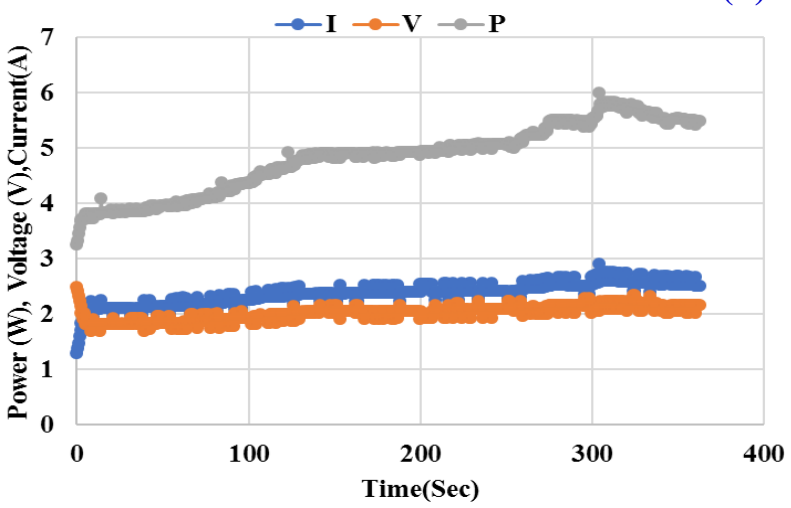

Figure 13. Experimental measurements of INC-MPPT when the both sides temperature are increased and rapidly changed, (a)hot and cold sides temperature, (b) current, voltage and power at these temperature values

In the fourth test, TEG system has been tested and compared when the TEG module was connected to a $16 \Omega$ resistive load through a DC-DC converter integrated with INC-MPPT and directly without INC-MPPT at $205.4^{\circ} \mathrm{C}$ hot side temperature and $46.9^{\circ} \mathrm{C}$ cold side temperature as shown in Figure 14 . This figure includes the current, voltage and power with applying INC-MPPT through the time from 0 to $25 \mathrm{sec}$ and the direct connection without INC-MPPT was through the time from 26 to $29 \mathrm{sec}$. The experimental results show that, the output power using the INC-MPPT algorithm is $11.9 \mathrm{~W}$ and $1.9 \mathrm{~W}$ without applying INCMPPT at the same resistive load $(16 \Omega)$, the same applied temperature and the same operating conditions. This means that, the harvested power has duplicated by 6.26 time by using MPPT. 


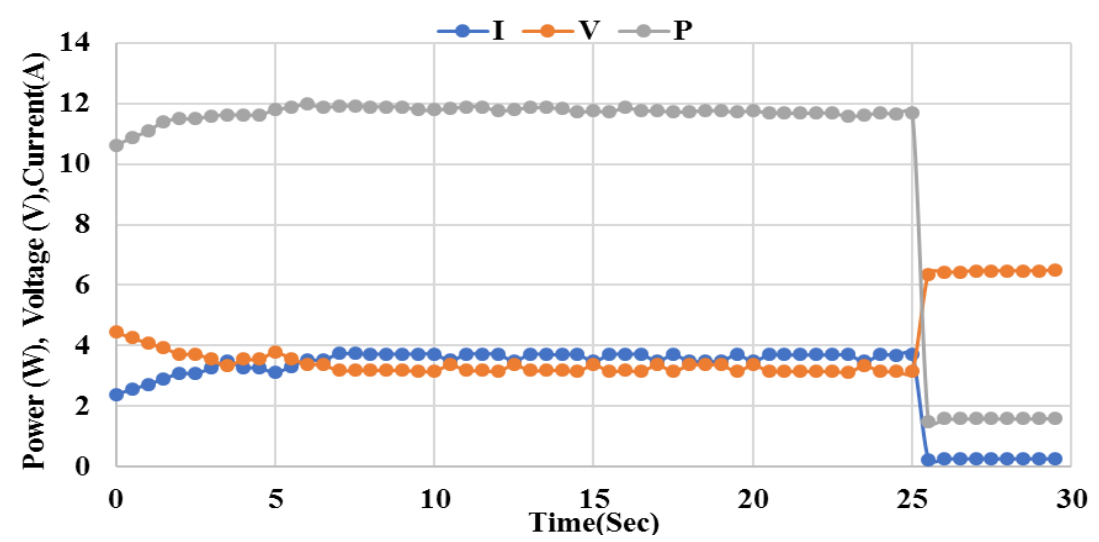

Figure 14. Experimental results of the current, voltage and power at $T H=205.4^{\circ} \mathrm{C}$ and $T C=46.9^{\circ} \mathrm{C}$ with INC-MPPT and direct connect without MPPT (hot side and cold side are constant)

To ensure the accuracy of the proposed system, the experimental and simulation results have been compared with the available industrial data sheet at the same values of temperature difference as shown in Figure 15 (a). Experimental and simulation results show that, the efficiency of the INC-MPPT techniques, which is estimated from Equation (19), has been changed from $96.9 \%$ to $98.6 \%$ for the simulation tests and from $88 \%$ to $98 \%$ for the experimental tests depending on the temperature difference applied on the TEG module as shown in Figure 15 (b)

Efficiency $\%=\frac{\text { output power of MPPT algorithm }}{\text { power of manufacturing data sheet }} \times 100$.

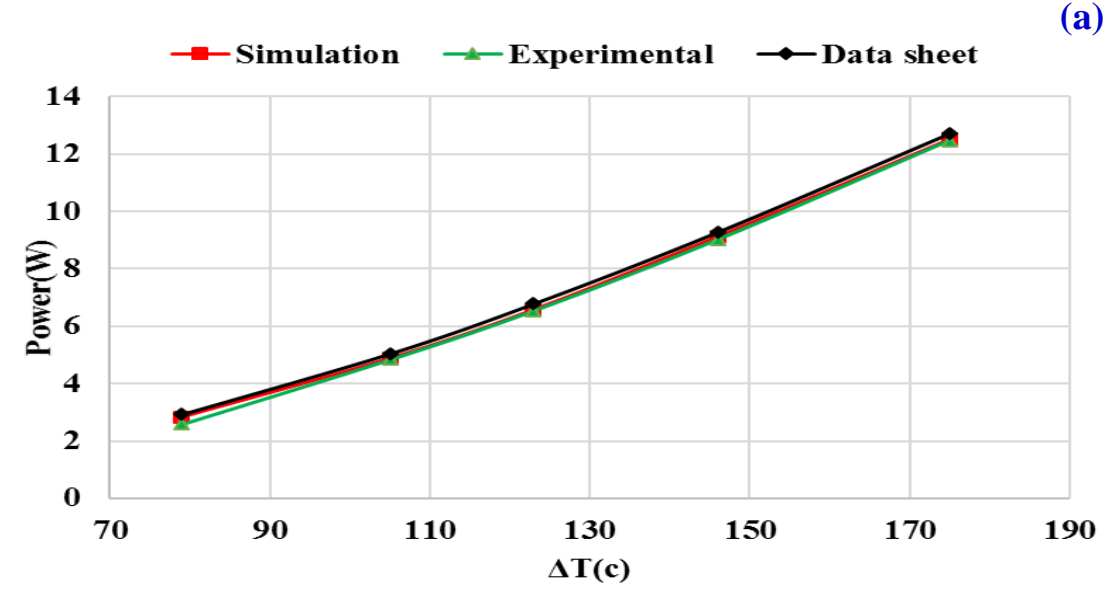

(a)

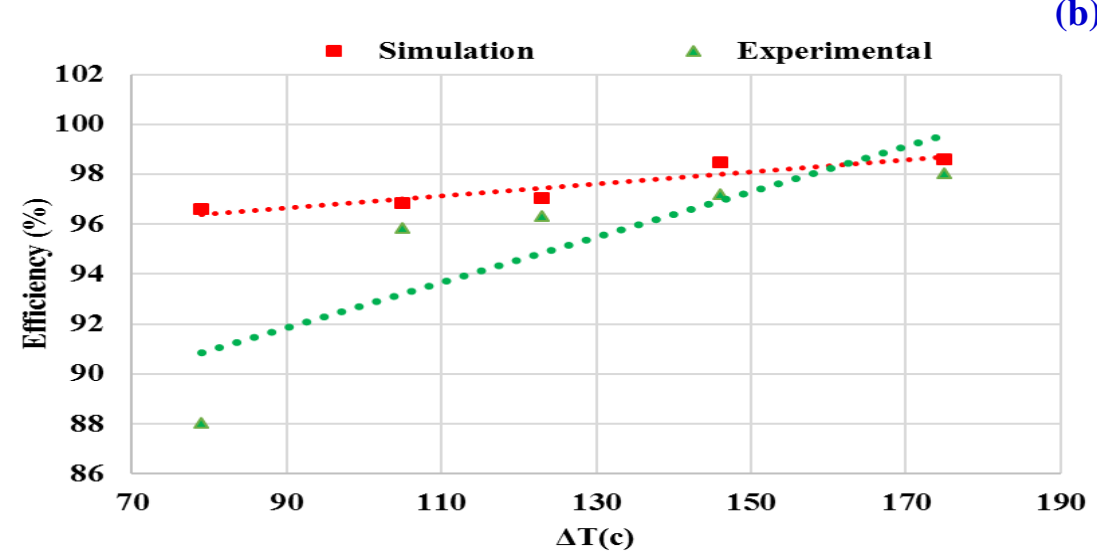


Figure 15. Experimental and simulation results comparing with the manufacturing data sheet at the different values of the temperature difference (a) Average power of the TEG module, (b) INC-MPPT efficiency

\section{CONCLUSION}

The TEG testing system has been proposed and implemented to simulate different operating conditions of waste heat energy applications. Commercial HZ-14HV TEG module connected to a DC-DC boost converter with INC-MPPT has been simulated, implemented and tested at different operating conditions. A low-cost Arduino microcontroller has been used to control the DC-DC boost converter and maximize the output power of the TEG module and used as a data acquisition system to measure current, voltage and temperature on the both sides of the TEG module and store them on computer. Simulation and experimental results prove that, the proposed TEG testing system with the INC-MPPT method can achieve the maximum output power of the TEG module with good accuracy, low fluctuation around the MPP at rapid changes of temperature and at any operating condition and give maximum efficiency $98.6 \%$ for the simulation results and $98 \%$ for the experimental results, also output power has been duplicated by more than six times applying INC-MPPT algorithm comparing with the direct connection.

\section{CONFLICTS OF INTEREST}

No conflict of interest was declared by the authors.

\section{REFERENCES}

[1] Sundarraj, P., Roy, S. S., Taylor, R. A., and Maity, D., "Performance analysis of a hybrid solar thermoelectric generator", Energy Sources, Part A: Recovery, Utilization and Environmental Effects, 38(20): 2977-2984, (2016).

[2] Shanmugam, S., Veerappan, A.R., and Eswaramoorthy, M., "An experimental evaluation of energy and exergy efficiency of a solar parabolic dish thermoelectric power generator", Energy Sources, Part A: Recovery, Utilization and Environmental Effects, 36(17): 1865-1870, (2014).

[3] Siddique, A.R.M., Mahmud, S., and Heyst, B. Van., "A review of the state of the science on wearable thermoelectric power generators (TEGs) and their existing challenges", Renewable and Sustainable Energy Reviews, 73(1): 730-744, (2017).

[4] Now, U.P.T.O., and Description, G., "Experimental 5-Kw Thermoelectric Generator", Energy, 2(1): 275-279, (1962).

[5] He, W., Zhang, G., Zhang, X., Ji, J., Li, G., and Zhao, X.,"Recent development and application of thermoelectric generator and cooler", Applied Energy, 143(1): 1-25, (2015).

[6] Champier, D. "Thermoelectric generators: A review of applications", Energy Conversion and Management, 140: 167-181, (2017).

[7] Twaha, S., Zhu, J., Yan, Y., \& Li, B. A., "Comprehensive review of thermoelectric technology: Materials, applications, modelling and performance improvement", Renewable and Sustainable Energy Reviews, 65: 698-726, (2016).

[8] Patil, D.S., Arakerimath, R. R., and Walke, P.V.,"Thermoelectric materials and heat exchangers for power generation - A review", Renewable and Sustainable Energy Reviews, 95(1): 1-22, (2018). 
[9] Mamur, H., and Ahiska, R., “Application of a DC-DC boost converter with maximum power point tracking for low power thermoelectric generators", Energy Conversion and Management, 97(1): 265 $272,(2015)$.

[10] Elzalik, M., Rezk, H., Shehata, E.G., Thomas, J., and Mostafa, R.,"Thermoelectric Power Generation System- Simulation and Experimental Investigation", IEEE Twentieth International Middle East Power Systems Conference, 978(1): 320-225, (2018).

[11] Elzalik, M., Abdalla, Y.S., and Mostafa, R.,"Maximum power point tracker ( MPPT ) techniques in pv systems", Engineering Research Journal, 140 (4): 1-15, (2013).

[12] Siviter, J., Montecucco, A., and Knox, A. R.,"Rankine cycle efficiency gain using thermoelectric heat pumps", Applied Energy, 140(1):161-170, (2015).

[13] Rezk, H., Fathy, A., and Abdelaziz, A.Y., "A comparison of different global MPPT techniques based on meta-heuristic algorithms for photovoltaic system subjected to partial shading conditions", Renewable and Sustainable Energy Reviews, 74(December 2016): 377-386, (2017).

[14] Kwan, T.H., and Wu, X.,"The Lock-On Mechanism MPPT algorithm as applied to the hybrid photovoltaic cell and thermoelectric generator system”, Applied Energy, 306-261, (2017).

[15] Montecucco, A., and Knox, A.R.,"Accurate simulation of thermoelectric power generating systems”, Applied Energy, 118, 166-172, (2014).

[16] Danandeh, M.A., and Mousavi, G.S.M., "Comparative and comprehensive review of maximum power point tracking methods for PV cells", Renewable and Sustainable Energy Reviews, 82(July 2017): 2743-2767, (2018).

[17] Shanmugam, S., Eswaramoorthy, M., and Veerappan, A.R.,"Modeling and analysis of a solar parabolic dish thermoelectric generator", Energy Sources, Part A: Recovery, Utilization and Environmental Effects, 36(14): 1531-1539, (2014).

[18] Karana, D.R., and Sahoo, R.R., "Effect on TEG performance for waste heat recovery of automobiles using $\mathrm{MgO}$ and $\mathrm{ZnO}$ nanofluid coolants", Case Studies in Thermal Engineering, 12(2): 358-364, (2018).

[19] Internet: "Hi-Z 14W HV Thermoelectric Generator ", Hi-Z Technology, Inc., http://hi-com/wpcontent/uploads/2017/05/Data-Sheet-HZ-14HV.pdf, (2019).

[20] Hauke, B. "Basic Calculation of a Boost Converter's Power Stage", Texas Instruments, (August):17, (2015). 